\title{
A STUDY OF SEVERITY OF STROKE AND HOMOCYSTEINE LEVEL IN SOUTHERN PART OF RAJASTHAN, INDIA
}

\author{
VINOD KUMAR MEHTA ${ }^{1}$, ABHIJIT BASU ${ }^{2}$, PRAHARSH H PATHAK ${ }^{3}$, AYUSHI JAIN ${ }^{4}$, NEHA SHARMA ${ }^{5 *}$ \\ ${ }^{1}$ Department of Neurology, Geetanjali Medical College and Hospital, Udaipur, Rajasthan, India. ${ }^{2}$ Department of Medicine, Geetanjali \\ Medical College and Hospital, Udaipur, Rajasthan, India. ${ }^{3}$ Critical Care Physician at Phoenix Hospital, Ahmedabad, Gujarat, India. \\ ${ }^{4}$ Department of Biochemistry, King George's Medical University, Lucknow, Uttar Pradesh, India. ${ }^{5}$ Department of biochemistry, Geetanjali \\ Medical College and Hospital, Udaipur, Rajasthan, India. Email: neha16.sharma@gmail.com
}

Received: 20 June 2021, Revised and Accepted: 19 September 2021

\section{ABSTRACT}

Objective: Till date, a very few prospective studies have examined the association between serum homocysteine levels and the risk of stroke and stroke subtypes in Indian populations.

Methods: A prospective, case - control study of Indian subjects 10-90 years of age was conducted using frozen serum samples from 103 participants in cardiovascular risk surveys collected from December 2017 to November 2018. By the end of 103, we identified 55 incidents of severe strokes, one control subject per case was selected by matching for sex, age, community, year of serum storage, and fasting status. Serum total homocysteine levels were measured by Cobas c-311.

Results: Compared with control subjects, total (n_206), hemorrhagic (n_106), and ischemic (n_87) strokes had higher geometric mean values of total homocysteine and higher proportions of homocysteine $-25.0 \mu \mathrm{mol} / \mathrm{L}$. Homocysteine was estimated after adjustment for body mass index, smoking, alcohol intake, hypertension, and other cardiovascular risk factors. The excess risk of total and ischemic strokes did not vary significantly according to sex, age, smoking status, or hypertensive status.

Conclusion: High total homocysteine concentrations were associated with the increased risk of total stroke, more specifically ischemic stroke) Capsuloganglionic and frontoparietal infarct (8 each)., among Indian men and women.

Keywords: Homocysteine, Stroke, Hemorrhage, Atherosclerosis.

(C) 2021 The Authors. Published by Innovare Academic Sciences Pvt Ltd. This is an open access article under the CC BY license (http://creativecommons.org/ licenses/by/4.0/) DOI: http://dx.doi.org/10.22159/ajpcr.2021v14i10.42674. Journal homepage: https://innovareacademics.in/journals/index.php/ajpcr

\section{INTRODUCTION}

High levels of homocysteine, in fasting or non-fasting state, have been reported to be more prevalent in patients with stroke asopposed to control subjects $[1,2]$. However, it can reflect an instead the cause, homocysteine concentrations can increase after the onset of acute stroke [3]. That's why, to decrease the bias, we have collected the desirable data for this prospective study. However, our findings from prospective studies were found to be incompatible. Various prospective studies of numerous subjects depicted a significant relationship among homocysteine and the probability of total [4- 8] or ischemic strokes, 8 while no correlation was found by others. Blockage in the cerebral artery, plaque formation, and embolus are usually found in ischemic stroke $[9,10]$. There have not been many prospective studies about the role of homocysteine on the probability of stroke, especially in South Rajasthan. Although few studies have shown; hyperhomocysteinemia was more prognostic for risk of lacunar infarction than other stroke subtypes [8]. It is important to investigate the significance of homocysteine levels and the risk of total stroke and other subtypes of stroke among Indian men and women. We hypothesized a priori that the risk of ischemic stroke was increased by hyperhomocysteinemia, more specifically right front-parietal infarct, left cerebella infarct, but not the risk of hemorrhagic stroke among Indian men and women. To test this hypothesis, we conducted a prospective, casecontrol study including men and women belonging to the southern population of Rajasthan, India, using stored serum samples.

\section{METHODS}

\section{Source of data}

Patients seeking treatment in the department of neurology and/or Medicine in Geetanjali Medical College and Hospital, Udaipur. From December 2017 to November 2019.
This study was conducted on 102 consecutive patients of age $>18$ years with a history of acute ischaemic stroke. Data were collected with a thorough history and clinical examination with detailed neurological evaluation along with appropriate investigations.

\section{Inclusion criteria}

Patients with a history of acute ischemic stroke with age $>18$ years of age either male or female, patients who presented within $48 \mathrm{~h}$ since the onset of symptoms according to the American association of Neurology criteria and confirmed by neuroimaging (magnetic resonance imaging and computed tomography scan) were included in this study.

(Definition of ischemic stroke: An episode of neurological dysfunction caused by focal cerebral, spinal, or retinal infarction). A written informed consent was obtained from all the study participants.

\section{Exclusion criteria}

Patients with a history of diabetes mellitus, structural or valvular heart disease, cerebral infarction associated with trauma or tumor. Patients with transient ischemic attack, HIV-AIDS, Vitamin B12 deficiency, venous infarct, coagulation disorders and patients who did not given consent were excluded from this study.

Analysis of sample was run on Cobas e-311 by Enzymatic Photometry. It is a technique which is estimates the depth of thickness of a solution through which light passes. Statistical analysis of result was done by pad prism graph. 


\section{RESULTS}

One hundred and two ischemic stroke incidents were identified during follow-up. Table 1 shows the characteristics of risk of total stroke incidents and of particular stroke subtypes were compared with control subjects. The average age was 52 years for total stroke, varying from 53 years to 79 years for subtypes. The systolic and diastolic blood pressure in patients who suffered a stroke was found to be higher in comparison to control group subjects. Intake of alcohol was higher in cases in comparison to control subjects for all stroke patients.

In the age group of 61 years-70 years, maximum number of patients were found. 6,9 , and 20 cases, respectively, of mild, moderate, and severe morbidity were observed.

\section{DISCUSSION}

The key highlight of our study was that the elevated concentrations of fasting blood serum total homocysteine were strongly associated with the increased prevalence of ischemic stroke attacks, especially Capsuloganglionic and Frontoparietal infarct in patients belonging to the southern part of Rajasthan, India. Patients in the highest quartile of homocysteine were two times higher with respect to the probability of occurrence of stroke as opposed to persons having low Homocysteine levels in blood serum. These associations did not alter substantially after adjustments were made due to the known cardiovascular risk factors, such as smoking and hypertension. No significant association was found between homocysteine levels and risk of hemorrhagic stroke. However, implications of elevated homocysteine on risk of intraparenchymal and subarachnoid hemorrhages separately were found to be uncertain due to the limited number of subjects.

As per our knowledge, this is the first study with the aim of spotlighting a significant relation between total homocysteine levels and consequential risk of ischemic strokes among the population of Southern Rajasthan. The extent of the correlation among homocysteine and risk of stroke was found to be congruous with the previous studies.

Age or status of smoking did not show any significant impact on the risk of ischemic stroke. Numerous previous studies have pointed out a stronger relationship between homocysteine and atherosclerosis and that of occurrence of stroke against hypertensive and non-hypertensive subjects. The link between ischemic stroke, hyperhomocysteinemia with hypertension is well grounded. Due to the fact that hypertension is the dominant risk factor for stroke. Exact underlying mechanisms and effect of hyperhomocysteinemia on risk of ischemic stroke are not yet clear.

Hyperhomocysteinemia causes a rise in arterial blood pressure, thus increasing the risk of ischemic stroke. In the current study, a higher homocysteine level of 3-_mol/L was associated with 2.8-mm Hg higher systolic and $1.2-\mathrm{mm} \mathrm{Hg}$ higher diastolic blood pressure levels taking in consideration the adjustment for age (year), sex, alcohol intake, and BMI with use of antihypertensive medication. We have concluded positive associations between serum homocysteine levels and risk of ischemic strokes, however, the relation of blood pressure with the same is yet to be made clear.

Elevated total homocysteine inflictsoxidative injury upon vascular endothelial cells and impairs the production of nitric oxide, a strong vascular relaxing factor, from the endothelium. Hyperhomocysteinemia also enhances adhesion of platelets to endothelial cells, promotes growth of vascularsmooth muscle cells, and is associated with higher levels of prothrombotic factors such as _-thromboglobulin, tissue plasminogen activator, and factor VIIc $[11,12]$.

The strong association between homocysteine levels and risk of lacunar infarction observed in our study should be noted (Tables 3 and 4). This finding is concordant with previous findings from clinical studies that show homocysteine levels were higher in inpatients with subcortical vascular encephalopathy, a type of dementia with subcortical diffuse white-matter lesions or Hyperhomocysteinemia can be affected by food intake, and thereby, it can be referred to as a flexible risk factor of a stroke. Folic acid and B-vitamins, required for the remethylation of homocysteine and formation of methionine, are the essential dietary contributing factor, and plasma homocysteine levels had been shown to decrease by daily supplementation [13-15]

Several trials and clinical interventions have been conducted to assess the role of supplementation on cardiovascular risk and increase the survival ratio of patients as well as healthy subjects $[13,15]$.

In our study serum homocysteine value was altered in 65 patients i.e. below $15 \mu \mathrm{mol} / \mathrm{L}$. The mean homocysteine value was 19.21 which

Table 1: Risk characteristics among cases and control subjects

\begin{tabular}{|c|c|c|c|c|c|c|c|c|c|}
\hline Subject/Control & $\mathbf{n}$ & Age years & $\mathrm{BMI} \mathrm{kg} / \mathrm{m}^{2}$ & $\begin{array}{l}\text { Systolic B.P. } \\
\text { (mmHg) }\end{array}$ & $\begin{array}{l}\text { Diastolic B.p. } \\
\text { (mmHg) }\end{array}$ & $\begin{array}{l}\text { Smoking } \\
\%\end{array}$ & $\begin{array}{l}\text { Alcohol } \\
\text { intake g/d }\end{array}$ & $\begin{array}{l}\text { HbA1C } \\
\%\end{array}$ & $\begin{array}{l}\text { CRP } \\
\mathrm{mg} / \mathrm{L}\end{array}$ \\
\hline \multicolumn{10}{|l|}{ Ischemic stroke } \\
\hline Case & 102 & $52 \pm 8.3$ & 23.7 & 138 & 82 & 27 & 15 & 5.2 & 0.86 \\
\hline Control subjects & 102 & $51 \pm 7.6$ & 22.18 & 134 & 78 & 22 & 12 & 4.3 & 0.44 \\
\hline Left capsuloganglionic infarct & 6 & $45 \pm 3.2$ & 22.15 & 136 & 76 & 14 & 13 & 5.4 & 0.65 \\
\hline Left cerebellar infarct & 7 & $53 \pm 5.6$ & 23.14 & 132 & 78 & 13 & 17 & 3.7 & 0.32 \\
\hline Left frontal infarct & 5 & $51 \pm 4.2$ & 22.17 & 134 & 78 & 12 & 15 & 5.6 & 0.25 \\
\hline Left medullary infarct & 3 & $62 \pm 8$ & 22.45 & 132 & 76 & 12 & 13.7 & 3.8 & 0.45 \\
\hline Left occipito-temporal infarct & 3 & $46 \pm 6.4$ & 21.35 & 136 & 78 & 26 & 12 & 3.6 & 0.65 \\
\hline Left parietal infarct & 5 & $51 \pm 4.3$ & 22.04 & 132 & 76 & 25 & 14 & 4.5 & 0.65 \\
\hline Left parietooccipital infarct & 4 & $46 \pm 3.9$ & 21.04 & 134 & 74 & 22 & 18 & 5.0 & 0.54 \\
\hline Left pontine infarct & 4 & $72 \pm 5.3$ & 22.35 & 136 & 78 & 25 & 13 & 4.6 & 0.56 \\
\hline Left thalamic infarct & 4 & $69 \pm 2.3$ & 21.34 & 138 & 80 & 12 & 15 & 5.0 & 0.67 \\
\hline Occipital infarct & 4 & $68 \pm 7.3$ & 22.58 & 132 & 78 & 27 & 12 & 4.8 & 0.68 \\
\hline Right capsuloganglionic infarct & 8 & $63 \pm 5.3$ & 21.07 & 132 & 76 & 26 & 13.7 & 4.7 & 0.84 \\
\hline Right frontal infarct & 6 & $59 \pm 3.4$ & 22.37 & 138 & 76 & 24 & 12 & 4.5 & 0.56 \\
\hline Right fronto-parietal infarct & 8 & $61 \pm 5.2$ & 21.45 & 134 & 80 & 22 & 11 & 5 & 0.74 \\
\hline Right medullary infarct & 2 & $61.87 \pm 3.2$ & 22.08 & 132 & 78 & 24 & 15 & 4.3 & 0.58 \\
\hline Right occipito-temporal infarct & 2 & $62 \pm 2$ & 21.08 & 136 & 80 & 28 & 13 & 3.7 & 0.67 \\
\hline Right parietal infarct & 6 & $58 \pm 4$ & 20.45 & 134 & 78 & 24 & 11 & 4.5 & 0.98 \\
\hline Right parietal occipital infarct & 4 & $55 \pm 8$ & 23.12 & 134 & 80 & 22 & 18 & 5 & 0.54 \\
\hline Right pontine infarct & 5 & $52 \pm 4$ & 22.14 & 132 & 78 & 28 & 13 & 4.1 & 0.68 \\
\hline Right thalamic infarct & 6 & $48 \pm 6$ & 21.34 & 136 & 76 & 27 & 16 & 3.8 & 0.56 \\
\hline
\end{tabular}

BMI: Body mass index 
Table 2: Case control differences in serum total homocysteine levels $(\mu \mathrm{mol} / \mathrm{L})$

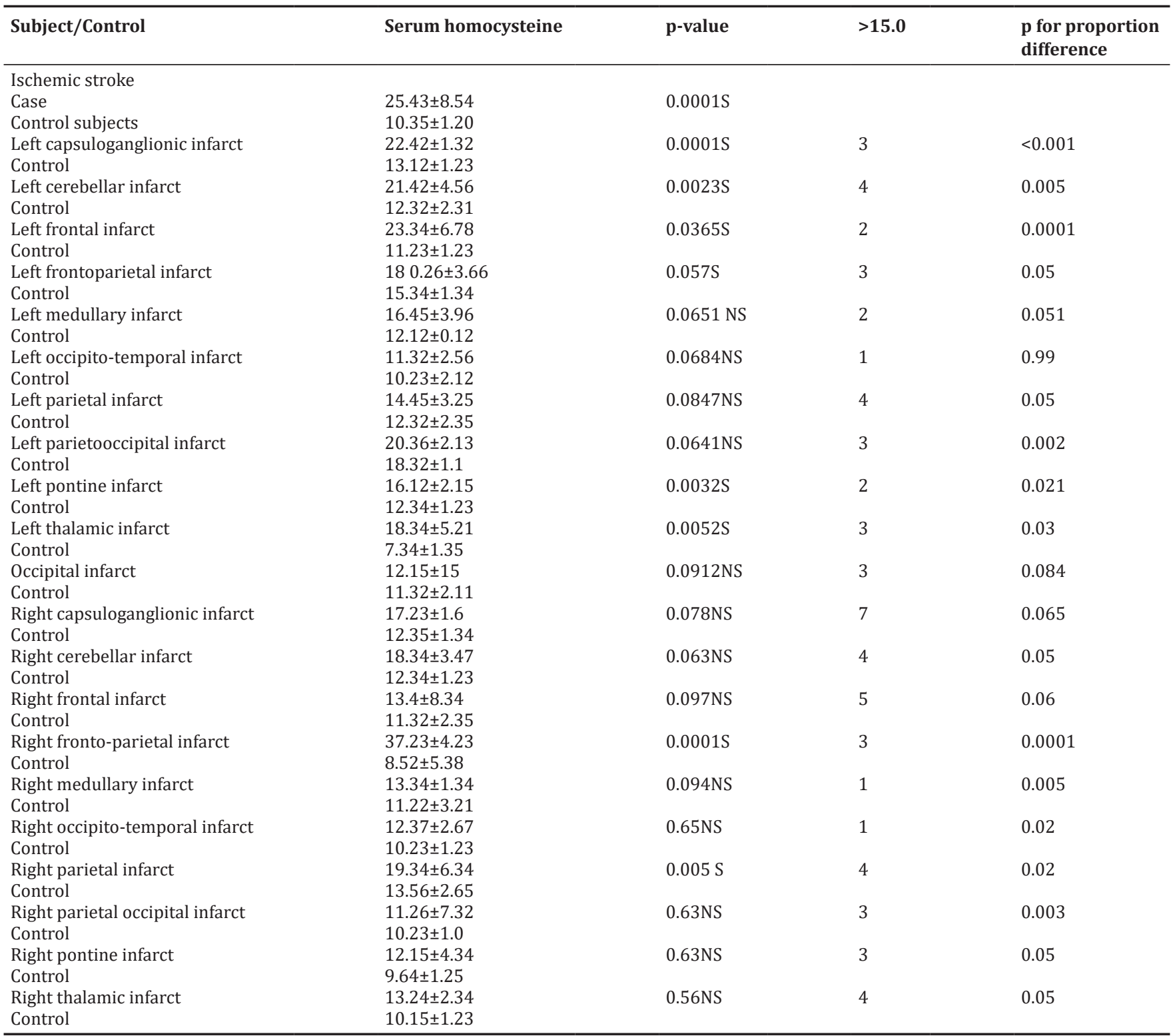

Table 3: Age-wise distribution and severity of stroke

\begin{tabular}{llll}
\hline Age group & Moderate & Moderate severe & Severe \\
\hline $11-20$ & 0 & 1 & 0 \\
$21-30$ & 1 & 2 & 0 \\
$31-40$ & 0 & 0 & 4 \\
$41-50$ & 2 & 3 & 3 \\
$51-60$ & 2 & 9 & 16 \\
$61-70$ & 6 & 9 & 20 \\
$71-80$ & 2 & 6 & 10 \\
$81-90$ & 1 & 3 & 2 \\
\hline
\end{tabular}

Table 4: Homocysteine level and severity of stroke

\begin{tabular}{llll}
\hline Homocysteine level & Moderate & Moderate severe & Severe \\
\hline $4-15$ & 5 & 12 & 21 \\
$16-20$ & 1 & 4 & 14 \\
$21-30$ & 8 & 14 & 17 \\
More than 30 & 0 & 3 & 3 \\
\hline
\end{tabular}

$\mathrm{p}=0.412$, not significant. Homocysteine value is not correlated with NIHSS score and it does not varies with NIHSS score was higher as compared to the study of Kwon et al. who reported 11.4 . There was no statistical difference found between the homocysteine level and severity of stroke, $\mathrm{p}=0.142$, and so Homocysteine value is not correlated ( $R=0.169, \mathrm{p}=0.489$ ) with NIHSS score and it does not vary with NIHSS score (Table 5).

Though in our study we have observed that there were no correlation in between serum homocysteine level and severity of stroke. While we have found higher level of serum homocysteine in patients of stroke with mild and moderate cases. We have found 21-30 $\mu \mathrm{m} / \mathrm{L}$ serum homocysteine levels in 8, 14, 17 mild, moderate, and severe cases, respectively. Similarly, there were more than $30 \mu \mathrm{m} / \mathrm{L}$ serum homocysteine levels in 3,3 moderate and severe cases of stroke. Higher values of serum homocysteine were there but differences were not statically significant $(p>0.05)$ in severe cases of stroke (Tables 1,2,5).

The result concluded in our study was in accordance with the study conducted by Wang et al. who also reported that the homocysteine values are not a predictive factor of the outcome at 3 months and 1 year after acute cerebral infarction among elderly patients [16,17]. 


\section{CONCLUSION}

Serum homocysteine levels were not correlated with the severity of stroke in a younger age group. Serum homocysteine level did not depict any relation with age and sex in the early age group. It is predictive risk factors for the severity of stroke only after 55 years of age.

\section{AUTHORS CONTRIBUTIONS}

All authors contributed equally for preparation of manuscript.

\section{CONFLICT OF INTEREST}

None.

\section{FUNDING}

None.

\section{REFERENCES}

1. Gorelick PB, Sacco RL, Smith DB, Alberts M, Mustone-Alexander L, Rader D, et al. Prevention of a first stroke: A review ofguidelines and a multidisciplinary consensus statement from the national stroke association. JAMA 1999;281:1112-20.

2. Wolfe CD. The impact of stroke. Br Med Bull 2000;56:275-86.

3. Reeves MJ, Bushnell CD, Howard G, Gargano JW, Duncan PW, Lynch G, et al. Sex differences in stroke, epidemiology, clinical presentation, medical care and outocmes. Lancel Neurol 2008;7:915-26.

4. Appelros P, Stegmayr B, Terent A. Sex differences in stroke epidemiology: A systematic review. Stroke 2009;40:1082-90.

5. Wassertheil-Smoller S, Hendrix SL, Limacher M, Heiss G, Kooperberg C, Baird A, et al. Effect of estrogen plus progestin on stroke in postmenopausal women: The women's health initiative: A randomized trial. JAMA 2003;289:2673-84.

6. Cox AM, McKevitt C, Rudd AG, Wolfe CD. Socioeconomic status and stroke. Lancet Neurol 2006;5:181-8.

7. Di Napoli M, Papa F. Inflammation, hemostatic markers, and antithrombotic agents in relation to long-term risk of new cardiovascular events in first-ever ischemic stroke patients. Stroke 2002;33:1763-71.

8. Lip GY. Fibrinogen and cardiovascular disorders. QJM 1995;88:155- 65 .

9. Hankey GJ, Eikelboom JW. Homocysteine and vascular disease. Lancet 1999;354:407-13.

10. Welch GN, Loscalzo J. Homocysteine and atherothrombosis. N Engl J Med 1999;338:1042-50

11. Refsum H, Smith AD, Ueland PM, Nexo E, Clarke R, McPartlin J, et al. Facts and recommendations about total homocysteine determinants: An expert opinion. Clin Chem 2004;50:3-32.

12. Malinow MR, Bostom AG, Krauss RM. Homocysteine, diet, and cardiovascular diseases: A statement for health care professionals from the nutrition committee, American heart association. Circulation 1999; $99: 178-82$

13. Homocysteine Lowering Trialists' Collaboration. Lowering blood homocysteine with folic acid based supplements: Meta-analysis of randomised trials. Homocysteine lowering trialists' collaboration. BMJ 1998:316:894-8

14. Ho GY, Eikelboom JW, Hankey GJ, Wong CR, Tan SL, Chan JB, et al. Methylenetetrahydrofolate reductase polymorphisms and homocysteine-lowering effect of vitamin therapy in Singaporean stroke patients. Stroke 2006;37:456-60.

15. Hankey GJ, Algra A, Chen C, Wong MC, Cheung R, Wong L, et al. Vitatops, the vitamins to prevent stroke trial: Rationale and design of a randomised trial of b-vitamin therapy in patients with recent transient ischaemic attack or stroke (nct00097669) (isrctn74743444). Int J Stroke 2007;2:144-50.

16. Kwon HM, Lee YS, Bae HJ, Kang DW. Homocysteine as a predictor of early neurological deterioration in acute ischemic stroke. Stroke 2014;45:871-3.

17. Wang W, Gao C, Yu C, Liu S, Hou D, Wang Y, et al. No association between elevated total homocysteine levels and functional outcome in elderly patients with acute cerebral infarction. Front Aging Neurosci 2017;9:70. 